\title{
Basic training module for vitreoretinal surgery and the Casey Eye Institute Vitrectomy Indices Tool for Skills Assessment
}

This article was published in the following Dove Press journal:

Clinical Ophthalmology

3I August 201 I

Number of times this article has been viewed

\author{
Steven Yeh' \\ Brian T Chan-Kai ${ }^{2}$ \\ Andreas K Lauer ${ }^{3}$ \\ 'Emory Eye Center, Emory University \\ School of Medicine, Atlanta, GA, USA; \\ ${ }^{2}$ Cullen Eye Institute, Baylor College of \\ Medicine, Houston, TX, USA; ${ }^{3}$ Casey Eye \\ Institute, Oregon Health and Science \\ University, Portland, OR, USA
}

Background: The purpose of this study was to design and implement a vitreoretinal training module that would be useful for ophthalmology residents and fellows to learn the basic maneuvers required in vitreoretinal surgery.

Methods: A prospective pilot study evaluating the training module was undertaken in 13 ophthalmology trainees (residents and vitreoretinal fellows) with varying levels of vitreoretinal training experience. A vitreoretinal training module was designed and consisted of a three-port vitrectomy setup (sclerotomy wound construction, infusion placement), intraocular tasks (core vitrectomy, driving the operating microscope, membrane peel, air-fluid exchange), and wound closure. Standard vitrectomy instrumentation, the VitRet eye (Phillips Studio, Bristol, UK) and vitreous-like fluid using dairy creamer and balanced saline were utilized. A five-point Likert scale, ie, the Casey Eye Institute Vitrectomy Indices Tool for Skills Assessment (CEIVITS), was devised to evaluate each component of the module. Vitreoretinal surgical maneuvers were digitally recorded and graded by an attending vitreoretinal surgeon. Linear regression and correlation were performed to evaluate the relationship between prior vitreoretinal experience and CEIVITS performance. The main outcome measures were correlation of vitreoretinal surgical experience and CEIVITS performance on simulated tasks using a basic vitreoretinal training module.

Results: Thirteen participants from postgraduate year 2 to postgraduate year 6 levels were evaluated. Nine participants were male and four were female. The median age of participants was 32 (range 30-36) years and surgical experience was 0-410 prior vitreoretinal surgical procedures. A positive correlation $(P<0.05)$ was observed between vitreoretinal surgical experience and CEIVITS performance on the following tasks: total score $(P=0.021)$, sclerotomy wound construction $(P=0.047)$, infusion line placement $(P=0.012)$, air-fluid exchange $(P=0.004)$, and wound closure $(P=0.032)$. Post module surveys showed that the majority of trainees felt that the vitreoretinal training module improved their understanding of vitreoretinal surgery. The nonbiohazardous nature of the setup was advantageous from sanitation and cost perspectives.

Conclusion: The implementation of our training module for residency and vitreoretinal fellowship was feasible and the CEIVITS adequately assessed basic vitrectomy maneuvers. Given that ophthalmologic and subspecialty instruction migrates from an apprenticeship to a competency-based model, the face and content validity makes the CEIVITS module a promising one in vitreoretinal surgical instruction.

Keywords: ophthalmology residents, vitreoretinal training, surgical

\section{Introduction}

The cognitive, kinesthetic, and experiential skills required for vitreoretinal surgery are typically acquired during ophthalmology residency and subspecialty fellowship 
training through an educational process involving didactics, wet laboratory experience, and mentored surgery.

Currently, postgraduate medical education is migrating from an apprenticeship model to a competency-based model, where greater importance is placed on formally incorporating surgical simulation in the training of surgeons. Ideally, the concept consists of the trainee surgeon acquiring the necessary fund of anatomic, medical, and microsurgical knowledge through didactics before moving to a practical testing environment or a surgical simulation laboratory. For the trainee, surgical simulation not only serves as an opportunity for practicing surgical maneuvers but also a venue for structured instruction and assessment of the performed surgical tasks necessary for basic vitreoretinal surgery. Once found competent in the simulation environment, the trainee may then implement those skills in the operating room under the guidance and mentorship of the supervising physician. In competency-based surgical education, the trainee who develops the cognitive, kinesthetic, and experiential surgical skills is periodically evaluated on their surgical task performance to establish that their skills are continuing to improve. ${ }^{1}$

Presently graduating ophthalmology residents are expected to have performed a minimum number of retinal procedures (ie, scleral buckling, posterior vitrectomy) as required by the Ophthalmology Residency Review Committee, ${ }^{2}$ and graduating vitreoretinal fellows are expected to have performed or assisted in a minimum of 75 scleral buckling procedures and in 100 posterior vitrectomy procedures for a variety of indications (eg, vitreous hemorrhage, endophthalmitis, giant retinal tear) as has been set out by the Association of University Professors of Ophthalmology Fellowship Compliance Committee. $^{3}$

Although a number of objective assessments for resident cataract surgery have been described, ${ }^{4-7}$ as well as specific wet laboratory curricula for assessing competency in cataract surgery, ${ }^{6}$ relatively few studies have addressed the means by which vitreoretinal surgical techniques are acquired and evaluated. Vitreoretinal surgery simulators using virtual reality technology have been reported, ${ }^{8-11}$ allowing the trainee to navigate both simple and complex vitreoretinal maneuvers. Virtual reality systems are exceedingly attractive approaches, although significant cost and access problems can preclude some training programs from incorporating these systems into their surgical curriculum. The development of artificial eye models has provided an additional means whereby basic vitreoretinal skills may be improved. ${ }^{12}$

The successful use of cadaveric eyes has been described previously for modeling anterior and posterior segment surgery. ${ }^{13-16}$ However, sanitation, theoretical infection risk, and logistic issues related to acquisition, handling, and disposal of human or nonhuman cadaveric eyes and the associated instrumentation and equipment necessary for a successful wet laboratory can present some disadvantages. For example, the use of ophthalmic instruments on cadaveric eyes precludes their further use on patients. In the case of human cadaveric eyes, corneal edema and lens clarity can preclude their use for practice vitreoretinal surgery.

The primary purpose of this study was to develop a practical vitreoretinal laboratory experience that would be advantageous for ophthalmology residents and vitreoretinal fellows. We also sought to develop a cost-effective training module devoid of potentially biohazardous material that could be adopted at most training institutions. In this context, we assessed the feasibility and face and content validity of a vitreoretinal training module using synthetic eyes as a potential instrument for the competency-based instruction of ophthalmology residents and vitreoretinal surgical fellows. In addition, we designed the Casey Eye Institute Vitrectomy Indices Tool for Skills Assessment (CEIVITS), an objective grading scheme using a five-point Likert scale to evaluate the specific surgical maneuvers performed. The design of the vitreoretinal training module and our experience with its implementation for ophthalmology residents and vitreoretinal fellows is described herein.

\section{Methods}

A vitreoretinal training module was designed using a Leica operating microscope system (Leica Microsystems, Wetzlar, Germany), the VitRet Eye Model (Phillips Studio, Bristol, UK) with artificial vitreous composed of $10 \%$ half-and-half cream/normal saline solution, and the Accurus vitrectomy system (Alcon, Fort Worth, TX).

\section{Preparation of model eye with vitreous-like fluid and digital recording apparatus}

Three milliliters of $10 \%$ half-and-half cream was injected into the VitRet Eye using a 27-gauge needle and exchanged for air. The leaflet of the artificial vitreous-filled VitRet Eye was then pinned into a Styrofoam head. The entire apparatus was centered under the operating microscope (Figure 1A and B), to which a digital recording system and an output video monitor were attached (Sony, Model DCR-TRV27, New York, NY, Figure 1C). The digital recording system 

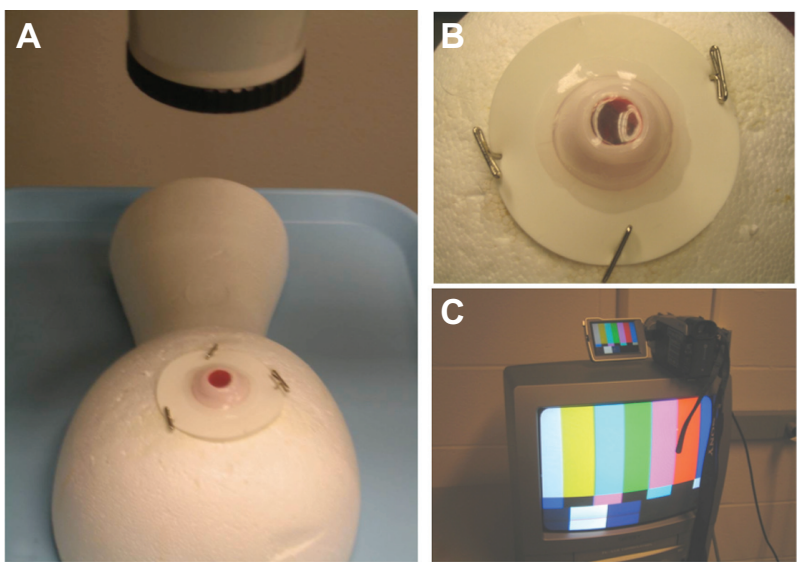

Figure I Operating microscope and digital recording setup. The VitRet eye is pinned to a Styrofoam head and centered under the operating microscope $(\mathbf{A})$ with its rubber leaflets attached to the apparatus with pushpins (B). This is performed after the injection of $10 \%$ half-and-half cream/saline mixture into the synthetic eye. The operating microscope is connected to the digital recording device with a video output for observation and evaluation (C).

was set up in this way so that surgical maneuvers could be reviewed and evaluated by the staff physician, by the trainee, or by a masked reviewer.

\section{Vitreoretinal module tasks}

In the training module, the following tasks were performed: sclerotomy wound construction, sewn infusion cannula placement, vitreous-like fluid removal from the central vitreous cavity ("core vitrectomy"), grasping a simulated epiretinal membrane with intraocular forceps, air-fluid exchange, and sclerotomy wound closure. Each surgical maneuver was separated into specific components that could be assessed using a five-point Likert scale by an observer either in real-time or later using digitally recorded video. The participating resident or fellow was able to assess the quality of their maneuvers by reviewing digital media.

Sclerotomy wound construction was separated into specific tasks for modeling and for evaluation purposes. For the sclerotomy wound construction task, trainees performed and were evaluated on using calipers to measure correctly the distance posterior to the limbus where the sclerotomy was to be placed (eg, $3.5 \mathrm{~mm}$ in this aphakic eye model), aiming the microvitreoretinal blade towards the center of the eye upon entry, and correctly placing a scleral plug. Securing the infusion was divided into placement of a 7-0 Vicryl horizontal mattress suture, checking to ensure that the infusion line was fluid-filled before constructing the inferotemporal sclerotomy with the microvitreoretinal blade, and evaluating and confirming by direct visualization, correct placement of the infusion cannula with an endo-illuminating pipe through the artificial cornea and pupil.

Components of basic vitrectomy techniques included using the light pipe to illuminate both the vitrector and posterior pole during core vitrectomy. During performance of core and mid-peripheral vitrectomy, driving, focusing and adjusting the microscope to illuminate the vitreous being removed were also evaluated (Figure 2A). For the task of membrane peeling, a disposable plano-concave vitrectomy lens coated with a viscoelastic or methylcellulose coupling agent was placed on the simulated cornea, and the microscope was focused on the posterior pole. A pair of 23-gauge end-grasping forceps (Grieshaber, Fort Worth, TX) was then introduced via the sclerotomy with the teeth closed and the endo-illuminating pipe in the surgeon's opposite hand or vice versa (Figure $2 \mathrm{~B}$ ). Next, the simulated epiretinal membrane at the posterior aspect of the VitRet Eye was grasped
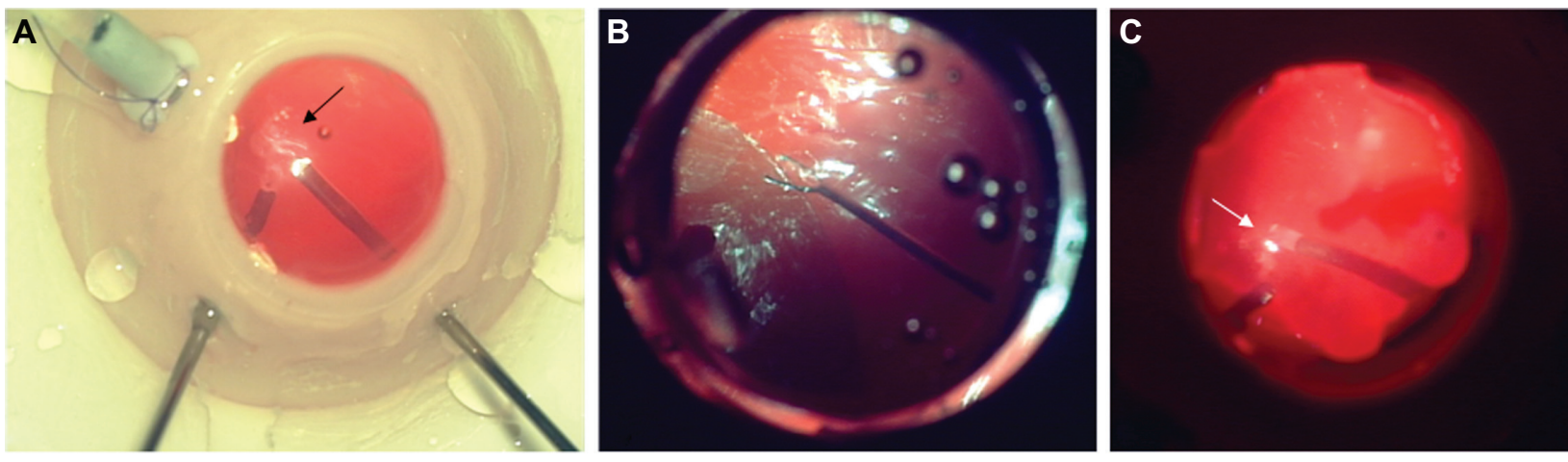

Figure 2 Core vitrectomy. Basic "core" vitrectomy may be performed following establishment of an infusion. The proteinaceous nature of the cream produces a vitreous-like appearance. With proper positioning of the endo-illuminating pipe, the wispy vitreous-like substance is visualized (black arrow) and engaged with the cutter (A). Membrane peel. Following adequate vitrectomy, the disposable contact lens is placed onto the cornea to visualize the membrane. End-grasping forceps may then be used to grasp and elevate the membrane taking care not to damage the underlying tissue (B). Fluid-to-air exchange. With the endo-illuminating light pipe and extrusion cannula, fluid to air exchange is performed and assessed. The identification of a subtle reflection (white arrow) at the air-fluid interface indicates that the extrusion cannula is at the meniscus of the fluid (C). 
and elevated, taking care not to touch the underlying simulated retinal surface. A fluid to air exchange was performed during which time the surgeon maintained the extrusion cannula at or slightly below the meniscus of the fluid-air level by using the light reflex change between air and the fluid-air interface. The extrusion cannula was gradually moved posteriorly as the meniscus descended and the efficiency of this maneuver could thus be evaluated (Figure 2C). Simulated sclerotomy closure was then performed with 7-0 Vicryl suture while the eye was air-filled. Airtight closure was then verified by applying balanced saline solution over the sclerotomy site to test for any evidence of wound gape.

\section{Casey Eye Institute Vitrectomy Indices Tool for Skills Assessment}

The CEIVITS evaluation form using a five-point Likert scale was designed to assess the components involved with the following surgical maneuvers: sclerotomy/wound construction, infusion line placement, driving and adjusting surgical microscope, performing core vitrectomy, performing air-fluid exchange, membrane peel maneuver, and wound closure (Figure 3).

\section{Performance and evaluation of vitreoretinal training module}

Following the design of the vitreoretinal training module, ophthalmology residents and vitreoretinal fellows participated in the module for instructional and research purposes. An instructional video illustrating the key basic vitreoretinal module maneuvers, which had been prepared by an attending-level vitreoretinal surgeon, was shown to each trainee twice. Each trainee then performed the vitreoretinal module tasks with a board-certified ophthalmologist with vitreoretinal training for prompting or additional instruction as needed (SY, BCK). All surgical maneuvers were digitally recorded and evaluated in a masked fashion using CEIVITS by an attending-level, boardcertified vitreoretinal specialist with more than five years of post vitreoretinal fellowship experience (AKL).

\begin{tabular}{|c|c|c|c|c|c|}
\hline & $\begin{array}{l}\text { Poor or inadequately } \\
\text { performed, inefficient } \\
\quad \text { or repetitive } \\
\text { maneuvers to execute } \\
\text { surgical step, poor } \\
\text { tissue handling }\end{array}$ & & $\begin{array}{l}\text { Performed with some } \\
\text { prompting or hesitation, } \\
\text { some additional } \\
\text { maneuvers needed but } \\
\text { satisfactory performance } \\
\text { overall }\end{array}$ & & $\begin{array}{l}\text { Performed well without } \\
\text { prompting or hesitation, } \\
\text { demonstrates respect for } \\
\text { tissues, time and motion }\end{array}$ \\
\hline \multicolumn{6}{|l|}{ Individual skills indices } \\
\hline $\begin{array}{l}\text { Sclerotomies: Correctly measures appropriate distance } \\
\text { from limbus for incision ( } 3.0-3.5 \mathrm{~mm} \text { if pseudophakic, } \\
3.5-4 \mathrm{~mm} \text { if phakic) }\end{array}$ & 1 & 2 & 3 & 4 & 5 \\
\hline $\begin{array}{l}\text { Sclerotomies: Correctly aims MVR blade towards center } \\
\text { of eye, avoids lens and retina, scleral plug placement }\end{array}$ & 1 & 2 & 3 & 4 & 5 \\
\hline $\begin{array}{l}\text { Infusion line placement: Ensures that infusion line is } \\
\text { fluid-filled prior to placement of the infusion line }\end{array}$ & 1 & 2 & 3 & 4 & 5 \\
\hline $\begin{array}{l}\text { Infusion line placement: Secure placement of the } \\
\text { infusion line and temporary suture placement }\end{array}$ & 1 & 2 & 3 & 4 & 5 \\
\hline $\begin{array}{l}\text { Infusion line placement: Verification of correct } \\
\text { placement of infusion line placement in vitreous cavity } \\
\text { with endoilluminating light pipe }\end{array}$ & 1 & 2 & 3 & 4 & 5 \\
\hline $\begin{array}{l}\text { Focusing, adjusting, and driving microscope after } \\
\text { entry into vitreous cavity: Keeping areas of surgery in } \\
\text { good focus, understanding the fashion to make } \\
\text { adjustments to microscope and viewing system }\end{array}$ & 1 & 2 & 3 & 4 & 5 \\
\hline $\begin{array}{l}\text { Performing core vitrectomy: Illuminating the ocular } \\
\text { fundus to highlight vitreous or area requiring attention } \\
\text { (eg, vitreous cutter and ocular fundus) }\end{array}$ & 1 & 2 & 3 & 4 & 5 \\
\hline $\begin{array}{l}\text { Engaging membrane with intraocular forceps: } \\
\text { Grasping and elevating the artificial epiretinal membrane }\end{array}$ & 1 & 2 & 3 & 4 & 5 \\
\hline $\begin{array}{l}\text { Air-fluid exchange: Adequate visualization of air-fluid } \\
\text { meniscus and placement of extrusion cannula at } \\
\text { meniscus, overall efficiency of air-fluid exchange }\end{array}$ & 1 & 2 & 3 & 4 & 5 \\
\hline $\begin{array}{l}\text { Wound closure: Watertight or airtight closure of } \\
\text { sclerotomies }\end{array}$ & 1 & 2 & 3 & 4 & 5 \\
\hline
\end{tabular}

Figure 3 CEIVITS five-point Likert grading scale. This grading scheme was developed to evaluate the fluidity and efficiency of each of the vitreoretinal surgery maneuvers. Each maneuver (ie, sclerotomy construction, infusion line placement, core vitrectomy, wound closure, air-fluid exchange, and membrane peel) is divided into individual components for assessment.

Abbreviation: CEIVITS, Casey Eye Institute Vitrectomy Indices Tool for Skills Assessment. 


\section{Post vitreoretinal module survey}

Following performance of the vitreoretinal training module, a post vitreoretinal module survey was administered to the trainees. Data collected included age, gender, years of ophthalmic surgery experience, postgraduate year level and number of prior vitrectomies performed at the time. The participants were asked their opinion of the following statements regarding the utility of the vitreoretinal training module in ophthalmic surgical education and the degree to which the model eye mimicked patient tissue using an ordinal grading scale (1, strongly disagree; 2 , disagree; 3 , neither agree nor disagree; 4, agree; 5, strongly agree), with "not applicable" if the trainee did not have enough data or experience to answer the question):

- Statement 1 "The vitreoretinal module helped me to understand or reinforce the basic steps required for vitreoretinal surgery"

- Statement 2 "The required components of the vitreoretinal module for basic vitreoretinal surgery adequately mimic the steps required of basic vitreoretinal surgery"

- Statement 3 "The tissues (synthetic eye, synthetic vitreous) mimic patient tissue"

- Statement 4 "Learning to accurately and efficiently perform the steps in this module may be helpful additions to residency or vitreoretinal fellowship education".

\section{Statistical analysis}

Descriptive and inferential statistics were performed using Microsoft Excel and GraphPad Prism 5 software. Linear regression and Pearson correlation was performed to determine if a relationship existed between the number of vitreoretinal procedures performed prior to participation in the vitreoretinal module and the individual CEIVITS scores following digital video grading.

\section{Results}

Thirteen ophthalmic trainees participated in this prospective pilot study evaluating a vitreoretinal training module. There were nine males and four female participants. Eight were ophthalmology residents (postgraduate year 2 through postgraduate year 4) and five were fellows (postgraduate year 5 and postgraduate year 6 ). The mean age of participants was 32 (range 30-36) years. The number of vitrectomy procedures performed by trainees prior to the training module was $0-410$. Demographic information and training level of the participants are summarized in Table 1.

Linear regression analysis and Pearson correlation (one-tailed) were performed to determine the relationship
Table I Demographic information and postgraduate year training level of participating ophthalmology residents and fellows

\begin{tabular}{ll}
\hline Total participants & \\
Male (\%) & $9(69)$ \\
Female (\%) & $4(3 \mathrm{I})$ \\
Training level (\%) & \\
PGY-2 & $6(46)$ \\
PGY-3 & $1(8)$ \\
PGY-4 & $1(8)$ \\
PGY-5 & $3(23)$ \\
PGY-6 & $2(15)$ \\
\hline
\end{tabular}

Abbreviation: PGY, postgraduate year.

of vitreoretinal surgical experience with individual and total CEIVITS performance scores. An alpha of 0.05 was considered statistically significant. Linear regression analysis demonstrated a statistically significant positive relationship between the number of vitrectomy procedures performed and CEVITS scores for the following categories: total CEIVITS score $(P<0.04)$, infusion line placement $(P<0.03)$, and air-fluid exchange $(P<0.007$, Figure 4$)$. Wound closure $(P<0.06)$ and sclerotomy wound construction $(P<0.09)$ approached statistical significance with linear regression analysis. Linear regression analyses evaluating vitreoretinal surgical experience and CEIVITS categories of focusing, driving and adjusting the microscope, performance of core vitrectomy, and membrane peeling tasks showed no clear statistically significant relationship $(P>0.05)$.

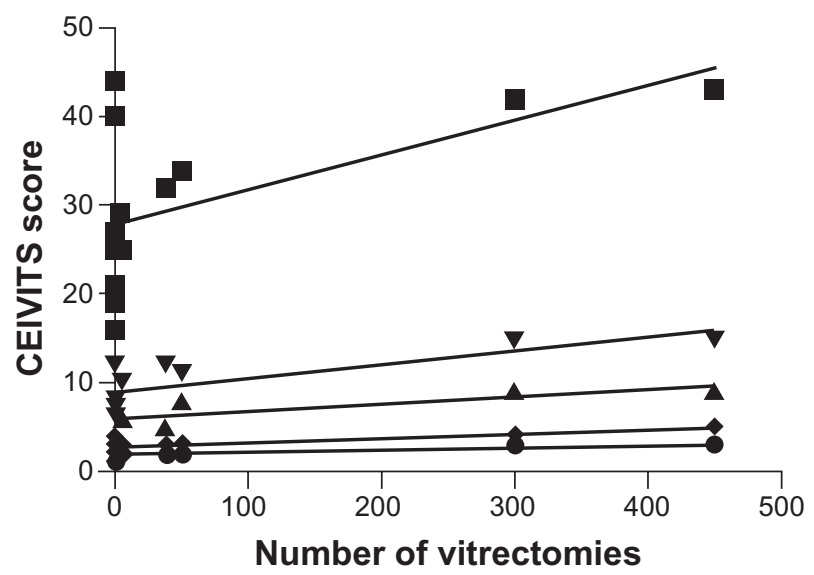

Figure 4 Linear regression analysis demonstrating relationship of vitreoretinal surgical experience to specific vitreoretinal surgical tasks performed in our module, as evaluated by the CEIVITS grading scale. A positive correlation was observed for VR surgical experience and the total CEIVITS score ( $\boldsymbol{\square})$, sclerotomy wound construction and placement $(\boldsymbol{\Delta})$, infusion line placement $(\boldsymbol{\nabla})$, air-fluid exchange $(\boldsymbol{\nabla})$ and wound closure (*). No clear correlation was identified for performance of core vitrectomy, focusing, adjusting and driving the microscope and membrane peeling tasks (data not shown).

Abbreviation: CEIVITS, Casey Eye Institute Vitrectomy Indices Tool for Skills Assessment. 
Pearson correlation of prior vitreoretinal training experience with the CEIVITS tasks was significant for total CEIVITS score $(P<0.02)$, sclerotomy wound construction $(P<0.05)$, infusion line placement $(P<0.01)$, air-fluid exchange $(P<0.003)$, and wound closure $(P<0.03)$. No statistically significant correlation was found for focusing, driving and adjusting the microscope, performance of core vitrectomy, and membrane peeling tasks $(P>0.05)$. The Pearson coefficients and individual $P$ values are summarized in Table 2.

Nine of $13(69 \%)$ participants returned their post vitreoretinal surgical training module surveys. The participants who returned vitreoretinal surgical training module surveys included three postgraduate year 2 ophthalmology residents, one postgraduate year 3 resident, one postgraduate year 4 resident, one postgraduate year 5 uveitis fellow, one postgraduate year 5 first year vitreoretinal surgical fellow, and two postgraduate year 6 second year vitreoretinal surgical fellows. Table 3 summarizes the post vitreoretinal surgical training module survey data for the individual statements. The majority of respondents agreed or strongly agreed with statements 1, 2, and 4. Specifically, most respondents felt that the vitreoretinal module helped them to understand or reinforce basic vitreoretinal surgical concepts (mean response score 4.9), adequately mimicked the steps required for basic vitreoretinal surgery (mean response score 4.3), and would potentially be helpful additions to ophthalmology residency or vitreoretinal fellowship education (mean response score 4.9). Fewer respondents agreed or strongly agreed that the tissues (synthetic eye, synthetic vitreous) adequately mimicked patient tissue (mean response score 3.3).

Table 2 Pearson product-moment correlation coefficients ( $r$ ) evaluating linear dependence of vitreoretinal surgical experience to total and individual surgical task performance evaluated by CEIVITS grade

\begin{tabular}{lll}
\hline VR training module task & $\begin{array}{l}\text { Correlation } \\
\text { coefficient }(\mathbf{r})\end{array}$ & P value \\
\hline $\begin{array}{l}\text { Total score } \\
\text { Sclerotomy wound construction }\end{array}$ & 0.57 & $0.021^{*}$ \\
(CEIVITS categories I and 2) & 0.48 & $0.047^{*}$ \\
$\begin{array}{l}\text { Infusion line placement (CEIVITS } \\
\text { categories 3-5) }\end{array}$ & 0.61 & $0.012^{*}$ \\
Focusing, driving, and adjusting & 0.22 & 0.232 \\
microscope & & \\
Performance of core vitrectomy & 0.23 & 0.221 \\
Membrane peeling task & 0.29 & 0.177 \\
Air-fluid exchange & 0.70 & $0.004^{*}$ \\
Wound closure & 0.53 & $0.032^{*}$ \\
\hline
\end{tabular}

Note: *Statistically significant difference.

Abbreviations: VR, vitreoretinal; CEIVITS, Casey Eye Institute Vitrectomy Indices Tool for Skills Assessment.

\section{Discussion}

Using this vitreoretinal training module, ophthalmology residents and vitreoretinal fellows were able to perform a variety of tasks required for basic vitreoretinal surgery. The trainee's performance of these skills was evaluated by a real-time observer for immediate feedback and prompting if necessary and by review of recorded video for evaluation using the CEIVITS grading scale. Surgical maneuvers that could be successfully performed using this synthetic eye infused with synthetic vitreous included sclerotomy wound construction placement, basic suturing technique (ie, placement of a horizontal mattress suture, closure of sclerotomies), vitreous cavity instrument maneuvering, adjusting, focusing, and driving the operating microscope, fluid to air exchange, and grasping a membrane on the surface of the retina.

The surgical maneuvers represented a few fundamental steps required for basic vitreoretinal microsurgery, and linear regression analysis showed a statistically significant relationship between prior vitreoretinal surgical experience and individual skills (ie, air-fluid exchange, infusion line placement) and the more global total CEIVITS score. A positive correlation was also observed between prior vitreoretinal surgical experience and total CEIVITS score, sclerotomy wound construction, infusion line placement, air-fluid exchange, and wound closure. The majority of respondents to a survey administered following the vitreoretinal module also felt that the vitreoretinal educational module was a helpful addition to vitreoretinal surgical instruction and mimicked the steps required for basic vitreoretinal surgery. However, whether the synthetic eye and vitreous adequately mimic patient tissue was not clear based on participant responses.

Limitations of this study include the small sample size of trainees and the lack of longitudinal information to determine whether an intervention (ie, additional surgical instruction) could improve the ability of trainees to perform basic surgical maneuvers. Limitations of the eye model include the extraocular and intraocular tasks that could not be performed owing to the anatomy of the synthetic eye and vitreous. Pertinent extraocular tasks that could not be performed using this setup included opening and closing of the conjunctiva and establishment of hemostasis. Pertinent intraocular tasks that could not be performed included creation of posterior vitreous separation because the artificial vitreous was injected into the eye and not adherent to retinal structures. Avoidance of the crystalline lens could not be performed because the VitRet eye lacks an artificial lens. Globe rotation for peripheral vitreous cavity maneuvers could not be simulated 
Table 3 Mean response scores for post vitreoretinal surgical module survey for individual statements regarding relevance of vitreoretinal surgical training module to ophthalmic vitreoretinal surgical education and closeness of synthetic eye model in mimicking patient tissue

\begin{tabular}{lll}
\hline Statement & Mean response (\# of responders) & Range \\
\hline $\begin{array}{l}\text { The vitreoretinal module helped me to understand or reinforce } \\
\text { the basic steps required for vitreoretinal surgery. }\end{array}$ & $4.9(9)$ \\
$\begin{array}{l}\text { The required components of the vitreoretinal module for basic } \\
\text { vitreoretinal surgery adequately mimic the steps required } \\
\text { of basic vitreoretinal surgery. }\end{array}$ & $4.3(6)$ \\
$\begin{array}{l}\text { The tissues (synthetic eye, synthetic vitreous) accurately mimic } \\
\text { patient tissue. } \\
\text { Learning to accurately and efficiently perform the steps } \\
\text { in this module may be helpful additions to residency } \\
\text { or vitreoretinal fellowship education. }\end{array}$ & $3.3(6)$ \\
\hline
\end{tabular}

because the artificial eye was fixed at the equator to the Styrofoam head. Although applying this vitreoretinal surgical module to noncontact wide-angle viewing systems including the binocular indirect ophthalmomicroscope system would be advantageous for surgical instruction, the inability of the artificial eye to rotate also limits simulation of peripheral vitreous base dissection.

Few problems were encountered in the development of this system for basic vitreoretinal technique. The consistency of the simulated sclera was slightly more rigid than that of cadaveric tissue; however, no problems with bending of the needle or dulling of the needle tip were observed. During fluid-air exchange, condensation developed on the posterior surface of the simulated cornea. This problem was remedied by coating the posterior surface of the artificial cornea with viscoelastic substance delivered via the sclerotomy or paracentesis incision or by using the extrusion cannula to wipe away the condensation, both of which are maneuvers valuable in real surgery when condensation develops on the intraocular lenses of pseudophakic patients.

The handling and disposal of instrumentation was easier in this clean wet laboratory compared with the time, cost, logistics, and resources needed to manage a laboratory that handles potentially biohazardous cadaveric tissue. Furthermore, the "clean" nature of the equipment enables training programs more latitude in the choice of location for practice surgery. Because the instrumentation is clean, any room can be used that can support the use of the current vitrectomy systems (ie, wet laboratory, operating room setting).

Educational models for posterior vitrectomy have been described in several contexts; these have included the use of cadaveric eyes, synthetic eyes, and more recently, virtual reality simulation. Grodin et al recently reported their prospective evaluation of ophthalmic trainees and attending staff physicians in an epiretinal membrane training task using the VRMagic Eyesi ${ }^{\circledR}$ v2.2 (Mannheim, Germany) system. ${ }^{11}$ Advantages of their setup included software providing immediate feedback about light toxicity and retinal damage. ${ }^{11}$ Iyer and Han reported a novel eye model for the practice of vitreoretinal membrane peeling. They described the modification of a rubber globe by removing the anterior segment and applying a coat of liquid skin bandage on the posterior pole to create an artificial vitreoretinal membrane. Using a disposable flat vitrectomy lens, the membrane peeling task could be practiced, creating a cost-effective and reusable practice eye model. ${ }^{12}$

One recent survey of senior ophthalmology residents in the US that the surgical experience at residency programs accredited by the Accreditation Council for Graduate Medical Education was suboptimal for vitreoretinal surgery. ${ }^{17}$ The training module described herein provides a feasible, cost-effective, and practical model for basic vitreoretinal training. Moreover, the CEIVITS five-point Likert scale was useful in the critical assessment of surgical technique with attention to respect for tissues, time and motion, vitreoretinal instrument handling, and bimanual dexterity. These components comprise a portion of an overall matrix recommended by a task force of the Department of Iowa for implementing the Accreditation Council for Graduate Medical Education core competencies for surgical education. ${ }^{18}$ Further assessment of this vitreoretinal training module will be needed to determine its precise role in the surgical education of ophthalmology residents and vitreoretinal fellows. The correlation of vitreoretinal surgical experience with individual and global task performance of basic vitreoretinal maneuvers and the positive response of ophthalmic trainees suggests that the Casey Eye Institute basic vitreoretinal training module in a clean wet laboratory and CEIVITS are promising for vitreoretinal surgical education. 


\section{Acknowledgments}

Supported in part by an unrestricted grant from the Research to Prevent Blindness, New York, and the Casey Eye Institute Ophthalmology Resident Education Fund. SY has received support from the Ronald G Michels Fellowship Foundation and Heed Ophthalmic Foundation.

\section{Disclosure}

These data were presented in part at the Educating the Educators Meeting in conjunction with the Association of University Professors of Ophthalmology Annual Meeting in Indian Wells, CA, January 28, 2009 and at the Retina Congress 2009, a combined meeting of the American Society of Retina Specialists, the Retina Society, and the Macula Society in New York, NY, October 1, 2009.

\section{References}

1. Lee AG. Graduate medical education in ophthalmology: Moving from the apprenticeship model to competency-based education. Arch Ophthalmol. 2008;126(9):1290-1291.

2. Accreditation Council for Graduate Medical Education. Ophthalmology resident operative minimum requirements. Available from: http://www. acgme.org/acWebsite/RRC_240/240_MinimumsOperativeTable.pdf. Accessed July 20, 2011.

3. Association of University Professors of Ophthalmology Fellowship Compliance Committee. Program requirements for fellowship education in surgical retina and vitreous. Available from: http://www.aupofcc.org/subspecialties/ retina/Retina_Fellowship_Guidelines.pdf. Accessed July 20, 2011.

4. Cremers SL, Ciolino JB, Ferrufino-Ponce ZK, Henderson BA. Objective Assessment of Skills in Intraocular Surgery (OASIS). Ophthalmology. 2005;112(7):1236-1241.
5. Fisher JB, Binenbaum G, Tapino P, Volpe NJ. Development and face and content validity of an eye surgical skills assessment test for ophthalmology residents. Ophthalmology. 2006;113(12):2364-2370.

6. Lee AG, Greenlee E, Oetting TA, et al. The Iowa ophthalmology wet laboratory curriculum for teaching and assessing cataract surgical competency. Ophthalmology. 2007;114(7):e21-e26.

7. Cremers SL, Lora AN, Ferrufino-Ponce ZK. Global Rating Assessment of Skills in Intraocular Surgery (GRASIS). Ophthalmology. 2005; 112(10):1655-1660.

8. Hikichi T, Yoshida A, Igarashi S, et al. Vitreous surgery simulator. Arch Ophthalmol. 2000;118(12):1679-1681.

9. Verma D, Wills D, Verma M. Virtual reality simulator for vitreoretinal surgery. Eye. 2003;17(1):71-73.

10. Rossi JV, Verma D, Fujii GY, et al. Virtual vitreoretinal surgical simulator as a training tool. Retina. 2004;24(2):231-236.

11. Grodin MH, Johnson TM, Acree JL, Glaser BM. Ophthalmic surgical training: A curriculum to enhance surgical simulation. Retina. 2008;28(10):1509-1514.

12. Iyer MN, Han DP. An eye model for practicing vitreoretinal membrane peeling. Arch Ophthalmol. 2006;124(1):108-110.

13. Sun R, Gimbel HV. In vitro evaluation of the efficacy of the capsular tension ring for managing zonular dialysis in cataract surgery. Ophthalmic Surg Lasers. 1998;29(6):502-505.

14. Borirak-Chanyavat S, Lindquist TD, Kaplan HJ. A cadaveric eye model for practicing anterior and posterior segment surgeries. Ophthalmology. 1995;102(12):1932-1935.

15. Porrello G, Giudiceandrea A, Salgarello T, Tamburrelli C, Scullica L. A new device for ocular surgical training on enucleated eyes. Ophthalmology. 1999;106(6):1210-1213.

16. Castellano D, Spraul J, Whitaker TE. A simple, cost-effective method for practicing phacoemulsification in the cadaveric eye. Ophthalmic Surg Lasers. 1998;29(3):253-256.

17. Shah VA, Reddy AK, Bonham AJ, Sabates NR, Lee AG. Resident surgical practice patterns for vitreoretinal surgery in ophthalmic training programs in the United States. Ophthalmology. 2009;116(4):783-789.

18. Lee AG, Carter KD. Managing the new mandate in resident education: A blueprint for translating a national mandate into local compliance. Ophthalmology. 2004;111(10):1807-1812.
Clinical Ophthalmology

\section{Publish your work in this journal}

Clinical Ophthalmology is an international, peer-reviewed journal covering all subspecialties within ophthalmology. Key topics include: Optometry; Visual science; Pharmacology and drug therapy in eye diseases; Basic Sciences; Primary and Secondary eye care; Patient Safety and Quality of Care Improvements. This journal is indexed on

\section{Dovepress}

PubMed Central and CAS, and is the official journal of The Society of Clinical Ophthalmology (SCO). The manuscript management system is completely online and includes a very quick and fair peer-review system, which is all easy to use. Visit http://www.dovepress.com/ testimonials.php to read real quotes from published authors. 